\title{
Chapter 5 \\ The Ethical Content of the Economic Analysis of Disasters: Price Gouging and Post-Disaster Recovery
}

\author{
Ilan Noy
}

\begin{abstract}
Economics, generally, is a discipline in which relatively little attention is devoted to language and terminology. As such, economists have not really attempted to define the concept of disasters very carefully, nor have they evaluated the ethics that are behind the economic analysis of disasters. Given this absence, we believe that a better understanding of the ways in which the discipline approaches the topic of disasters and its ethics is gained not by examining the multitude of definitions in the discipline, but by examining specific examples of topics that are contested within the economic literature on disasters and their ethical content. Outlining the main arguments and methodological approaches that economists use to think about these topics will, we hope, better clarify the general approach that economists use when embarking on disciplinary research on the topic of disasters. As such, we choose to focus on two topics: price gouging, and post-disaster economic recovery. The first is a topic that is explicitly ethically challenging from an economic perspective; the second involves many implicit ethical decisions that are almost never made explicit.
\end{abstract}

Keywords Price gouging · Economic recovery · Post-disaster · Economics and ethics

\subsection{Concepts and Economics}

Economics, generally, is a discipline in which relatively little attention is devoted to language and terminology. When terminology is defined, it is usually within the context of a statistical or a mathematical model that requires one to very clearly specify assumptions and relationships that follow from the definition used. As such, economists have not really attempted to define the concept of disasters very

\footnotetext{
I. Noy $(\triangle)$

School of Economics and Finance, Victoria University of Wellington,

Wellington, New Zealand

e-mail: ilan.noy@vuw.ac.nz 
carefully, unlike sister social sciences like geography who have been defining and refining the appropriate uses of this term for decades.

Many economists are perfectly happy with a definition of disasters that just specifies an ad-hoc and arbitrary threshold of fluctuation-be it in the hazard itself, or its impact — and call this 'a disaster'. For some, a disaster is thus a significant fluctuation in weather conditions (e.g., an unusual amount of rainfall), or a disaster is defined as a significant mortality or destruction associated with a trigger of some sort (often the trigger is not defined and just the level of mortality or destruction is observed). In other cases, it is not even the destruction that is measured, but rather the reduction in the flow of goods and services that are made or consumed after the trigger event. The level that determines 'significance' is also not well determined, with, for example, the two most important global datasets collecting economic statistics on disasters (Desinventar and EMDAT) using very different thresholds; and some in economics using other thresholds as well.

In the economics literature, one can therefore find dozens of definitions of what constitutes a disaster. Maybe the most general definition is the one proposed by the United Nations International Strategy for Disaster Risk Reduction (UNISDR): It is a "serious disruption of the functioning of a community or a society at any scale due to hazardous events interacting with conditions of exposure, vulnerability and capacity, leading to one or more of the following: human, material, economic and environmental losses and impacts." But this definition is vague enough so it encompassed many different conceptions of disasters. In some ways, every paper that deals with this topic in economics has its own unique definition, depending on the specific focus of interest, the methodological approach used, and the data that is employed within this methodology. Still, even within the papers that choose similar approaches and data, one can identify large variation in the use of the terminology of disasters. However, within each paper, the definition adopted is usually very clearly specified (even if very different from other work in the same area of interest). This is in contrast with other related concepts such as vulnerability or resilience that are typically very ill-defined; with relatively little interest in the economics literature in clarifying and more precisely identifying them (an exception is Rose 2007). In some respects, most economists apply the 'duck test' to these more controversial terms (whose definition is highly contested in other disciplines). For economists, therefore, 'a bird that walks like a duck, and swims like a duck, and quacks like a duck, is called a duck' and not much is gained, in this view, by trying to carefully define what a duck is.

Given this definitional chaos, we believe that a better understanding of the ways in which the discipline approaches the topic of disasters and its ethics is gained not by examining the main definitions in the discipline, but by examining specific topics that are contested within the economic literature on disasters. Outlining the main arguments and methodological approaches that economists use to think about these topics will better clarify the general approach that economists use when embarking on disciplinary research on the topic of disasters.

Maybe the biggest ethical challenge that is central to discussions in economics is the question of the distribution of income and wealth. This topic is also present in 
analysis of the economics of disasters, as both the impacts of disasters and recovery from them have distributional consequences. This topic is also central to discussions of public policy interventions before or after disasters (for example, in discussions of public insurance programs-see Owen and Noy 2017). Similarly, objections to the pervasive use of utilitarianism as the primary lens through which economic analysis is being conducted have also been raised within the context of disasters.

We choose to focus in this paper on two specific topics, price gouging, and postdisaster economic recovery, as these will enable us to cover much of the general arguments within the context of this chapter. Price gouging is a topic that is explicitly challenging from an economic-and-ethics perspective; the second, involves a lot of implicit ethical decisions that are almost never made explicit.

\subsection{The Problems of Price Gouging and Economic Recovery}

In the wake of a natural disaster, due either to destruction of existing stocks or the difficulty of transporting goods into the disaster site, necessities such as food, water, or gasoline are often scarce. This scarcity, a basic premise in economic analysis, raises concerns that vendors of these goods (and services) will engage in what is commonly known as "price gouging:" the practice of raising the price of these goods far above the pre-disaster market price. Many economists define their discipline as the study of mechanisms to allocate scarce resources, and as such the study of "price gouging" goes directly to the heart of economic analysis.

Many non-economists find price gouging intuitively morally objectionable, as it is perceived as greedy and exploitative. This critical attitude has resulted in the implementation of a multitude of laws banning price gouging, especially in the United States (Davis 2008). The economics profession, however, is much more ambivalent or even supportive of price gouging practices, as many economists have argued that laws against price gouging are counterproductive. These laws, according to the economists' interpretations, harm those in need instead of helping them, and many have argued furthermore that there is nothing morally objectionable about the practice.

The purpose of the following two sections will be firstly to examine the economists' claim that permitting price gouging maximizes the total welfare of those in a disaster zone (a utilitarian argument), and secondly to address the vaguer ethical argument that, even if price gouging maximizes total welfare, it is morally benign and should be permissible. We will argue firstly that there is no straightforward answer as to whether price gouging is total-welfare maximizing in the way economists use these terms. Surprisingly, we could not find any empirical work by economists that attempts to examine the evidence for this. Secondly, we argue there are ethical reasons to suggest that price gouging can be morally impermissible, although our analysis suggests these reasons are not decisive.

In the last section of this chapter, we examine another ethically fraught question that has been examined by economists: the recovery from disasters. In this last 
section, we describe some of the ways in which recovery is being assessed, and examine the economic and ethical content of these assessments. We conclude that section by some additional observations.

\subsection{Economic Analysis of Price Gouging}

Economics is a discipline tightly engaged with practical distributional considerations, and there are three primary practical arguments advanced in favor of the idea that price gouging is total-welfare maximizing: (1) it discourages hoarding; (2) it ensures efficient allocation of resources to those most in need; and (3) it incentivizes producers to increase supply in the disaster-affected area. We will consider each one of these in turn. One should note, however, that a ban on price gouging should probably not be considered in isolation. Bans on price gouging may be accompanied by supplementary policies, such as a ban on hoarding (restricting the amounts of specific goods people are allowed to buy) or the provision of subsidies and assistance to producers and importers/suppliers of these goods into the affected region.

Let us firstly consider hoarding. The basic argument here is simple: if prices are low, individuals in disaster zones will buy large quantities of necessities, significantly more than they will realistically require, "just to be safe." Evidence of this sort of behavior has been observed before in the wake of natural disasters; see, for example, the discussion of the 2011 Japanese earthquake in Cavallo et al. (2014) but no general evidence for this as in Parker (2018). These excessive purchases will be greater in frequency and magnitude the more uncertainty there is about the impact of the disaster and the ability of local authorities to continually supply necessities. This uncertainty will be more pronounced the bigger the disaster, so that we should observe more hoarding when supply is more limited and authorities less able to react, compounding matters and making the post-disaster situation significantly worse. Given the inability of authorities to operate efficiently in these areas, we should doubt the efficacy of regulatory responses, and should therefore prefer market-place responses like price increases.

High prices, according to this view, cause people to think twice before buying arbitrarily large quantities, and thus prevent excessive hoarding and ensure that goods are more equally distributed across the affected populations rather than just to those that were first in the queue.

A possible response to this concern of hoarding is to implement anti-hoarding laws. Yet the potential effectiveness of these laws is unclear. The maximum amount that individuals are allowed to purchase must by necessity be set reasonably high so that individuals in genuine need of large amounts can still purchase them; but that still leaves a lot of room for other individuals to buy more than they need.

A basic premise in much of economics is that people respond to incentives. In this case, when laws and incentives clash, when the law can easily and costlessly be circumvented (for example by multiple visits to the store), and when enforcement will be non-existent (as law enforcement will have 'bigger fish to fry' in disaster 
zones), economists expect these laws to be largely ineffective. There is little empirical evidence either way, particularly because few places actually implement antihoarding laws, so the presumption among economists is that since effective implementation of anti-hoarding laws and similar quantity-mechanisms is impossible, one needs to resort to price mechanisms (price gouging) to effectively and efficiently allocate scarce resources.

There are, however, three other considerations that suggest that perhaps price gouging may not be necessary or effective as a response to hoarding. The first is simply that hoarding is already discouraged through social norms that condemn hoarders, especially in crisis situations. If social norms can lead to efficient and equitable allocation of these scarce necessities, economic (price) incentives may not be necessary. The second is that price gouging, rather than reducing the net amount of hoarding, simply means that only higher-income individuals will hoard (as even post-gouging prices will appear relatively low to high-income individuals when compared to the high stakes and risks present in a disaster zone). Hoarding, in this description, will be done just by the rich, rather than by those that are first in the queue. As such, the outcome achieved in an environment that allows price gouging is not any better than what one expects to observe when hoarding is permissible and the queue is the main allocation mechanism.

The third argument, one that has not received sufficient attention in the literature, is that gouging may in fact increase hoarding. Consider the impact of price gouging on a rational agent with imperfect information. High prices are a strong signal that the good is scarce, which incentivizes the individual to hoard the good. If there is no scarcity, the individual knows that if they unexpectedly run out they can simply return to purchase more; by contrast, if the good is scarce, the individual will buy a large amount of the good to hedge against the risk of running out. If, on the other hand, there is a prohibition on gouging, then low prices may signal either an inability to raise them due to the law, or an abundance of the good.

In general, and especially in post-disaster chaos, information is not easily available. Thus, consumers will not necessarily know, if prices are low, whether there is any scarcity. However, if prices are allowed to increase, and price gouging occurs, consumers will have a definite signal of scarcity, increasing their incentive to hoard. Therefore, and maybe counter-intuitively, the higher the price, the stronger the incentive to hoard more; leading to a cycle of increased prices and increased hoarding. This is of course mostly speculation, as we have no observational (empirical) research on the topic, but hopefully it serves to show that the assumption that price gouging is effective in preventing hoarding should not be taken for granted.

Of course, humans are not perfectly rational agents responding only to information and price signals, and if we introduce the possibility of irrationality, the effect may be even more extreme. There is substantial evidence to suggest that our estimation of the value of goods is formed irrationally through the confluence of a variety of factors, only one of which is price (Ariely 2008). This means that lower prices may cause individuals to irrationally believe that goods are not high-value and therefore not worth hoarding, whilst high prices may cause them to re-evaluate their behaviour, and "scare" them into hoarding, rather than away from it. 
Overall, then, it is unclear whether price gouging's effect on people's propensity to hoard goods is a legitimate or significant argument in favor of allowing the practice. Yet the issue of hoarding is the most minor of the three practical arguments for price gouging. We can next consider the issue of efficient allocation.

One of the most valuable functions of a system of prices is ensuring that scarce resources are allocated efficiently; that is, they are allocated to the individuals who need them most. The more utility an individual derives from consuming a particular good, the more money that individual will be willing to pay to buy that good. In the context of price gouging, if prices are high, this will ensure that only individuals whose need for the high-priced goods is acute will purchase them. If, by contrast, prices are kept low, everyone will attempt to buy the goods, so that many of the goods will end up with individuals who do not require them as intensely. This leads to a suboptimal allocation of these goods across consumers.

There are two problems with this argument. The first is that it is contingent on the assumption that the goods being discussed are worth significantly more to some people than others: given that we are mostly discussing basic necessities like food, water, and energy, this assumption seems somewhat doubtful. One might argue that since individuals might have differing initial quantities of these goods, they may be worth much more to some individuals (who do not have large supplies of them) than to others (who do). Yet, as we will expand upon later, individuals with large existing contingency supplies of these goods are likely to be wealthy and therefore undeterred by high prices, and the individuals who most need these necessities are likely to lack easy access to large quantities of money.

The second is that although the idea of using prices to determine the extent to which people value a good is sound in most cases, it does suffer from one major flaw: money is a highly imperfect proxy for utility, because people have vastly differing incomes. This is a fairly intuitive concept, but one that may merit a digression. A basic fact about most commodities, including money, is that they are subject to diminishing marginal returns: the more you have of it, the less utility an additional unit of it provides. So, for example, $\$ 20$ provides far more utility for a homeless person with no wealth than it does for a millionaire. This principle applies conversely: if a homeless person were to lose $\$ 20$, they would lose far more utility than a millionaire would. Essentially, a certain quantity of money has a different utility value for each principal, a value that is significantly determined by that person's wealth and income.

So consider that a particular good in a disaster situation is worth 25 units of utility (henceforth 'utils') to a person of low income, and 20 utils to a person of high income. Even though the higher-income individual values the good less, they may be willing to pay significantly more for it, since money is worth less to them than it is to the lower-income individual. Thus, prices are only very roughly able to determine who values a good most across individuals.

Moreover, banning price gouging does not mean that the market entirely loses the ability to allocate the goods to those who value them most. Instead, the mechanism of prices based on monetary units is replaced by a different mechanism, one which may be distributed more equally across consumers: a mechanism of time 
prices. In a post-disaster situation where goods are scarce and cheap (due to antigouging laws) and everyone wants to acquire them, what often happens is that long lines form at the entrances to distributors. In such a situation, the individuals most likely to acquire the goods are those who are most willing to stand in lines for long periods of time.

Willingness to expend time may be a better proxy for an individual's valuation of a good than price, since it is immune to the distortionary effect of income differences (we all experience $24 \mathrm{~h}$ in any day). However, it is of course subject to a variety of other potential distortionary effects and is still imperfect. A possible objection to the use of time instead of prices is that it forces people to spend hours of precious time in a post-crisis situation queueing, when higher prices could clear out the lines and save a lot of time. Yet conversely, of course, high prices could have a crippling impact on the finances of individuals in a post-crisis situation by forcing them to expend large amounts of money on necessities. Thus, price gouging could be equally harmful in interrupting recovery.

Overall, we have hopefully cast doubt on the idea that price gouging is necessary or even appropriate for addressing the economic question of efficient allocation post-disaster. Yet efficient allocation is still not the most significant argument in favor of price gouging. That honor is reserved for the arguments surrounding supply. Essentially, high prices for particular goods in a disaster area accomplish two things: they signal to producers outside the disaster zone that there is a scarcity of these high-priced goods, and they provide the incentive to these producers to transport goods rapidly into the area. With high prices, there is plenty of profit to be made, and the profit motive may be a strong incentive to produce and import more of the scarce goods (e.g. water) into the disaster-affected region.

From an economics perspective, with its emphasis on incentives, this is a convincing argument. Banning price gouging would do little to incentivize increased supply of essential goods to the post-disaster areas. In fact, incentives may be reduced as the cost of transporting a good may rise post-disaster (e.g. when railways are damaged). However, alternative policies can be introduced to encourage suppliers to bring goods into the area: the simplest policy might be for the government to directly supply the scarce goods by buying them elsewhere and transporting them into the region; potentially distributing through regular retail supply chains. But, the government may also just provide subsidies to producers who sell necessities in the area, thus providing the same incentives to producers that high prices would whilst ensuring that the burden does not fall too harshly on consumers. This would also neatly solve another common argument against anti-gouging laws, which is that they can fail to account for increased costs or risk involved in supplying goods to a disaster zone; a generous subsidy would ameliorate that concern as well.

There are potential practical problems with the idea of using subsidies, and, as we previously observed, these practical concerns are frequently important in economic analysis. For one, their use might divert money away from other areas of government-sponsored disaster relief. Additionally, whilst they may be effective at encouraging large, established retailers who can easily access these subsidies, they may not work for other sources of supply. Informal suppliers, such as individual 
entrepreneurs with the ability to transport goods into disaster areas, may not find it that easy to document their actions and access government support (Zwolinski 2008). Maybe most importantly, the administrative costs of implementing such a subsidy, especially at short-notice, maybe be quite high.

The efficiency and feasibility analysis outlined above is typical for economics; most of the economics literature concerns itself with similar debates about the abilities of policies to deliver an improvement in outcomes. These outcomes are usually framed within discussions of implementability and efficiency, rather than, for example, moral considerations. Yet, before moving on to a brief discussion of the ethical issues surrounding price gouging from an economics perspective, we briefly outline two arguments against the idea that price gouging maximizes total welfare.

The first objection is the potential issue of monopolistic control of the available supply. In a post-disaster situation, travel is often inhibited and going long distances in search of alternative providers can become difficult and dangerous. Competition is thus curtailed. This means that the ability of different providers to compete with each other is drastically reduced, and may mean that providers become oligopolistic or even, monopolists. Under these circumstances, giving providers the flexibility to change prices as they wish may result in prices significantly above the marketclearing price, whereas forcing them to keep prices essentially fixed avoids allowing firms the privilege of using their newly found monopoly power to set prices above the market-clearing (and allocatively most efficient) rate.

Secondly, there are reasons to think that individuals of lower income systematically require these goods more intensely than individuals with higher income do. Higher-income individuals are more likely to be prepared for disaster situationsfor example, with emergency stocks of water or food (e.g., Stats NZ n.d.; FEMA 2013 - and therefore may not be in desperate need of necessities to the extent that people of lower income are. Since under price gouging, the individuals purchasing the goods are likely to be predominantly of higher incomes, even if there are more net goods supplied, this may be a worse outcome than if fewer goods were supplied, but to a more diverse mix of higher and lower income households. All of this analysis, of course, is consequentialist.

In conclusion, it is not at all clear that price gouging is an efficient tool of welfare maximization. There is no empirical evidence on the topic, and much work needs to be done before it will be possible to conclusively say whether allowing price gouging is preferable even on consequentialist terms. Next, we discuss the ethical issues pertaining to price gouging - after all, it is possible that even if it is consequentially efficient, other aspects of price gouging might incline us towards banning it.

The focus we will select here-whether it can be immoral for the state to select a particular characteristic as the basis for making distributive decisions - and is not related to the previous arguments about price gouging themselves, but to the ways economists consider them. Economists often avoid making normative ethical claims, which means they avoid large components of the discussion on policy issues.

Jeremy Snyder points out that price gouging undermines "equitable" access to necessities because individuals of lower income are priced out of the market (Snyder 
2009a, b). He argues that because of this suppliers have a moral duty not to raise prices; doing so involves treating others inequitably and undermining their dignity.

This is an interesting position, but it is very difficult to link culpability for a systemic, market-wide wrong (if, indeed, it is a wrong at all) to particular individuals who are just responding to the demands of the market. It is more interesting, instead, to consider the situation from the perspective of the state, which is making a simple decision: on which basis will resources be distributed? Will they be distributed randomly (to whomever turns up to the shops first) or on the basis of a similarly random characteristic, which is difficult to pin down to a particular group (e.g. willingness to wait in line)? Or, alternatively, will they be distributed systematically to individuals of higher income?

Zwolinski responds to this objection by noting that random chance is a morally irrelevant basis for decision-making in the same way as income is a morally irrelevant characteristic (Zwolinski 2009). Yet we think that most economists (and others) will intuitively believe random chance to be a morally superior mechanism of allocation when compared to making decisions based on certain pre-existing differences between individuals (such as wealth). Why is this?

It is clear, firstly, that our intuitive repulsion to the idea of using income or wealth as a basis for allocation is not due simply to the fact that some characteristic is chosen in the place of random chance. If, instead, the decision had been based on whoever happens to be wearing orange shirts, few would find it to be intuitively morally objectionable. So, it is clear that our indignation is contingent on the fact that the differentiating characteristics — e.g. wealth—are salient features that are significant in our society. So, in order to fully deal with this argument, we need a theory to explain why making allocative decisions on the basis of significant observable characteristics is immoral.

It is possible that our repulsion is not due to the fact that the decision itself is objectionable, but that it instead reveals something objectionable or bigoted about the character of the individual making it. In the case of price gouging, then, because the decision to allow it is motivated not by any bigotry or preference but simply by a desire for an efficient market, permitting price gouging should be perfectly acceptable. Yet we will argue that there may be a rational basis for our repulsion, even if the motives behind the action are innocent.

The first reason for this is that it is impossible for the sellers in this case to be making a decision that is truly objective. They will inevitably share some characteristics with certain groups of people in the crisis situation and will undoubtedly have their own opinions and biases. In this context, it is impossible for any decision that selects a particular group of people (the buyers) to have entirely pure motives-even the decision to privilege market efficiency. The only way for the agent to avoid the potentially corrupting influence of their context is to select a method of allocation that is not premised on any of the facts of the situation or characteristics of the people involved, and is therefore context-free: specifically, random allocation.

Secondly, if we take the use of random chance as a natural baseline, then the choice to make an allocative decision on any other basis implicitly involves elevating that characteristic into a status of moral relevance. If that characteristic is one 
that is integral to people's identities and the way they interact with the world, then the decision to privilege one such characteristic over the others involves degrading the dignity and identity of everyone whose characteristics are being used as a way to deny them resources.

These principled arguments are not decisive, but importantly in the context of our chapter, ones that are rarely engaged on by economists. Economics, in general, prefers to use what it inaccurately views as 'morally neutral'- the criterion of efficient allocation, and rarely examines the implicit moral content of that choice. Economists are either consequentialists - for whom the process of allocation is less important and the efficiency criterion is very important, or libertarians-for whom any government intervention in prohibiting the operations of the market has to pass a very high threshold of justification (usually some significant market imperfection). However, as we observed, there are reasons to cast some doubts about the consequentialist benefits of price gouging, and equally about the libertarian argument against banning it; see also Rapp (2005) and Brewer (2007) for additional discussion of these arguments.

\subsection{Long-Term Recovery}

Disasters lead to significant direct damage to infrastructure, to raw materials, crops, extractable natural resources, the natural environment and, most tragically, to people. Disasters, however, also cause more indirect impacts - often termed "losses" by economists - though the terminology, as we pointed out earlier, is not universally discussed nor agreed upon. Economic losses refer to the flow of economic activity, in particular the production of goods and services, which will not take place as a consequence of the disaster, both in the short and possibly in the long term. These economic losses have as much impact on society's long-term prosperity and wellbeing as the immediate damages to physical infrastructure and people. One can even contemplate long-term losses on experienced well-being, and even indirect mortality (Noy 2016b).

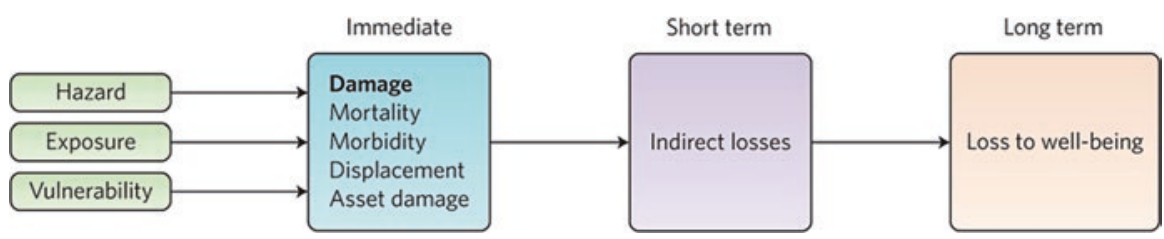

Source: Noy (2016a)

The standard approach in economics to deciphering the long-term recovery prospects of postdisaster economies starts with the assumption that the recovery from the destruction will be complete: that is to say, an economy will experience accelerated growth postdisaster until it returns to its previous trajectory (or status 
quo). From Adam Smith and John Stewart Mill-founding fathers of modern economics - to Gary Becker - a more recent Nobel prize winner in Economics—much of the profession assumes that indeed this is what typically happens after large shocks (be they triggered by natural hazards or by man-made triggers such as wars or large accidents).

Over the past 30 years, there have been several challenges to this idea of inevitable full recovery within the profession. If, for example, a disaster changes the competitive advantage of production in a specific region, even temporarily, businesses and customers may end up going elsewhere, leading to long-term decline. This scenario describes fairly well the fate of the Japanese Port of Kobe after a destructive earthquake hit the city in 1995. Despite the fact that the port was reconstructed in less than two years after suffering severe damage, the container traffic that used to flow through it-it was previously one of the busiest ports in the world-never returned to its pre-disaster level (Chang 2000; duPont et al. 2015).

An alternative theory is that the long-term trajectory may even turn out to be beneficial. This is usually termed 'creative destruction.' This interpretation of creative destruction revolves around the idea that buildings and infrastructure destroyed by disasters are replaced by newer and more productive alternatives, which allows more productive use of available resources-better public transportation networks, smarter electricity or telecommunication grids, or more energy-efficient factories, for example. This improved infrastructure leads to additional prosperity. In theory, positive long-term impact can occur not only from technological innovation, but also from "build-back-better" policies that allow for improved reconstruction (perhaps through better zoning).

Most examinations of moderately prosperous countries, at least at the national level, find that there are no significant long-run national impacts associated with natural disasters, even when these are catastrophic (Cavallo et al. 2013). Researchers who disagree, however, always find evidence that disasters hinder and delay (possibly permanently) development and creation of prosperity. Indeed, for small and poor countries that have trouble accessing resources for reconstruction, for example Haiti, it is unfortunately plausible to expect a long-term decline in well-being as a result of the 2010 earthquake (Katz 2013).

In countries with fewer resources, natural disasters can also have more longlasting, negative effects through their impact on education and health. The damage to the educational infrastructure and transportation networks, for example, can lead to a decline in educational achievements, which in turn has implications for the long-term prospects of affected individuals. Most troubling is research that shows a decrease in years-of-schooling for children who were in utero during the destructive 1970 Peruvian earthquake (Caruso and Miller 2015). In the Peruvian case, this negative impact on educational attainments persisted even into the next generation, so that the children of mothers affected by the natural disaster while the mothers were still in utero also experience lower educational achievement.

New Orleans in the aftermath of Hurricane Katrina is a particularly well-studied case. The hurricane has had a particularly profound and enduring impact on the local population of New Orleans. Many of the households displaced by the hurri- 
cane have remained dispersed in neighboring states and cities. Income prospects elsewhere played a significant role in a household's decision whether to return or not. In this case, lower-income households found it particularly difficult to return as the neighborhoods least likely to get rebuilt were populated more densely by the (mostly African-American) poor. These households also found that their prospects had improved "in exile," further reducing their incentive to return (Deryugina et al. 2018). A decade after the hurricane, the population of the city is almost $20 \%$ lower than it was the week before Katrina hit the Gulf Coast. But this net decline hides a bigger churning of people and more fraying of the city's original social fabric.

In cases where the politics and power relations are skewed, a disaster may also serve as a catalyst for changes that can be either positive or negative. In Haiti, for instance, there was much hope that its under-performing economy and dysfunctional government would be improved in the disaster's aftermath with the large inflow of foreign assistance. Tragically, this was not the case, and the government today is perceived as dysfunctional as before the quake (Katz 2013). Similar hopes were expressed, for example, with respect to New Orleans pre-hurricane underperforming public education system.

However, as Naomi Klein documents in her book, the Shock Doctrine (2010), there are also many instances in which entrenched powers use the 'opportunity' of disasters to further solidify their control and push through changes that they favour. These changes would have otherwise faced fiercer resistance. This resistance either dissipates or is easier to ignore because of the 'fog of war' during the disaster's aftermath.

More optimistic scenarios can also be found. A build-back-better economy may be an unintended consequence of the changes wrought by the disaster. The Mississippi Flood of 1927, for example, led to the modernization of agriculture in the flooded areas, inevitably because the day laborers (mostly African-American) left. This outmigration forced farmers to adopt new technologies. In contrast, where labour shortages were not acute, modernization did not take place (Hornbeck and Naidu 2014).

All of this analysis, however, is purely an examination of ultimate consequences, and ignores the process that led to the examined outcomes. But, even from a consequentialist perspective, it is often incomplete. The standard framework in the social sciences identifies disaster risk as a confluence of the hazard, exposure to the hazard, and the vulnerability of the exposed populations (and assets). As such, an analysis of recovery should also examine the impact of the process on these three components (though the hazard risk is usually assumed constant in the time spans implicitly examined). What happens to this risk triangle (hazard, exposure, and vulnerability) is clearly important, but is often ignored in the economic analysis. For example, one can imagine a trade-off between reducing exposure and reducing vulnerability in post-disaster recovery. Such a trade-off is identified in the case of Sri Lanka's coastal reconstruction policy in the aftermath of the 2004 Aceh tsunami. Ingram et al. (2006) argue that the initial post-disaster law prohibiting any reconstruction within 100 or $200 \mathrm{~m}$ of the high tide mark emphasized reducing exposure at the (significant) cost of increasing vulnerability of the impacted populations. 
Those previously living along the coast were economically dependent on access to that coast (mostly as their income was either from tourism or from fishing). Thus, the enforced distance from the ocean was diminishing their livelihoods and increasing their vulnerability. Later, the government backed away from this law, exactly because it realized the increased vulnerability it was creating.

Currently, economists lack satisfactory tools to sufficiently consider these tradeoffs. While modeling well-being and measuring social welfare has been developing within the profession, the frameworks that will allow one to considerately evaluate the various consequentialist trade-offs inherent in a post-recovery process are still in their infancy. And, if one were to eschew consequentialist analysis, economics as a methodological approach does not have much to add to the conversation.

From a more practical, policy-oriented perspective, the main message of this chapter is that economists need to be more explicit about the ethical content of their analysis and evaluate it more thoroughly in those terms. Consequentialism, in and of itself, is an ethical choice, but even within this framework, the reigning one in Economics, there are many ethical choices that are made, often implicitly. These ethical choices are important in determining policy recommendations, and economists ignore them at their peril.

\section{References}

Ariely, Dan. 2008. Predictably irrational: The hidden forces that shape our decisions. New York: Harper.

Brewer, Michael. 2007. Planning disaster: Price gouging statutes and the shortages they create. Brooklyn Law Review 72: 1101.

Caruso, German, and Sebastian Miller. 2015. Long run effects and intergenerational transmission of natural disasters: A case study on the 1970 Ancash Earthquake. Journal of Development Economics 117: 134-150.

Cavallo, Eduardo, Sebastian Galiani, Ilan Noy, and Juan Pantano. 2013. Catastrophic natural disasters and economic growth. The Review of Economics and Statistics 95 (5): 1549-1561.

Cavallo, Eduardo, Alberto Cavallo, and Roberto Rigobon. 2014. Prices and supply disruptions during natural disasters. The Review of Income and Wealth 60 (S2): 449-471.

Chang, Stephanie. 2000. Disasters and transport systems: Loss, recovery, and competition at the Port of Kobe after the 1995 earthquake. Journal of Transport Geography 8 (1): 53-65.

Davis, C.W. 2008. An analysis of the enactment of anti-price gouging laws. Unpublished master's thesis, Montana State University, USA. http://scholarworks.montana.edu/xmlui/bitstream/ handle/1/1145/DavisC0508.pdf?sequence=1. Accessed 21/04/2018.

Deryugina, Tatyana, Laura Kawano, and Stephen Levitt. 2018. The economic impact of hurricane Katrina on its victims: Evidence from individual tax returns. American Economic Journal: Applied Economics 10 (2): 202-233.

duPont, William, Ilan Noy, Yoko Okuyama, and Yasuhide Sawada. 2015. The long-run socioeconomic consequences of a large disaster: The 1995 earthquake in Kobe. PLoS One 10 (10): $\mathrm{e} 0138714$.

FEMA. 2013. Personal preparedness in America: Findings from the 2012 FEMA national survey. Washington, DC: Federal Emergency Management Agency. Web. 15 Nov. 2016.

Hornbeck, Richard, and Suresh Naidu. 2014. When the levee breaks: Black migration and economic development in the American South. American Economic Review 104 (3): 963-990. 
Ingram, Jane C., Guillermo Franco, Cristina Rumbaitis-del Rio, and Bjian Khazai. 2006. Postdisaster recovery dilemmas: Challenges in balancing short-term and long-term needs for vulnerability reduction. Environmental Science \& Policy 9 (7): 607-613.

Katz, Jonathan. 2013. The big truck that went by: How the world came to save Haiti and left behind a disaster. New York: St. Martin's Press.

Klein, Naomi. 2010. The shock doctrine: The rise of disaster capitalism. New York: Metropolitan Books.

Noy, Ilan. 2016a. Tropical storms: The socio-economics of cyclones. Nature Climate Change 6: 343-345.

- 2016b. New ways of defining success in post-disaster recovery. World Politics Review $5 / 7 / 16$

Owen, Sally, and Ilan Noy. 2017. The unfortunate regressivity of public disaster insurance: A quantitative analysis of a New Zealand case. CESifo Discussion Paper \#6540.

Parker, Miles. 2018. The impact of disasters on inflation. Economics of Disasters and Climate Change 2 (1): 21-48.

Rapp, Geoffrey. 2005. Gouging: Terrorist attacks, hurricanes, and the legal and economic aspects of post-disaster price regulation. Kentucky Law Journal 94: 535.

Rose, Adam. 2007. Economic resilience to natural and man-made disasters: Multidisciplinary origins and contextual dimensions. Environmental Hazards 7 (4): 383-398.

Snyder, Jeremy. 2009a. What's the matter with price gouging? Business Ethics Quarterly 19 (2): 275-293.

- 2009b. Efficiency, equity, and price gouging. Business Ethics Quarterly 19 (2): 303-306.

Stats NZ (n.d.). How prepared are New Zealanders for a natural disaster? http://www.stats.govt.nz/ browse_for_stats/people_and_communities/Households/natural-disaster-how-prepared-nzers. aspx. Accessed 21/04/2018.

Zwolinski, Matt. 2008. The ethics of price gouging. Business Ethics Quarterly 18 (3): 347-378. . 2009. Dialogue on price gouging. Business Ethics Quarterly 19 (2): 295-303.

Open Access This chapter is licensed under the terms of the Creative Commons Attribution 4.0 International License (http://creativecommons.org/licenses/by/4.0/), which permits use, sharing, adaptation, distribution and reproduction in any medium or format, as long as you give appropriate credit to the original author(s) and the source, provide a link to the Creative Commons license and indicate if changes were made.

The images or other third party material in this chapter are included in the chapter's Creative Commons license, unless indicated otherwise in a credit line to the material. If material is not included in the chapter's Creative Commons license and your intended use is not permitted by statutory regulation or exceeds the permitted use, you will need to obtain permission directly from the copyright holder.

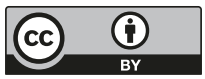

